\title{
Landsat: A Global Land-Imaging Project
}

Across nearly four decades since 1972, Landsat satellites continuously have acquired space-based images of the Earth's land surface, coastal shallows, and coral reefs. The Landsat Program, a joint effort of the U.S. Geological Survey (USGS) and the National Aeronautics and Space Administration (NASA), was established to routinely gather land imagery from space; consequently, NASA develops remote-sensing instruments and spacecraft, then launches and validates the satellites. The USGS then assumes ownership and operation of the satellites, in addition to managing all ground-data reception, archiving, product generation, and distribution. The result of this program is a visible, long-term record of natural and human-induced changes on the global landscape (table 1).

\section{A Brief History of the Landsat Program}

In the mid-1960s, stimulated by U.S. successes in planetary exploration using unmanned remote-sensing satellites, the Department of the Interior, NASA, and the Department of Agriculture embarked on an ambitious effort to develop and launch the first civilian Earth-observation satellite. Their goal

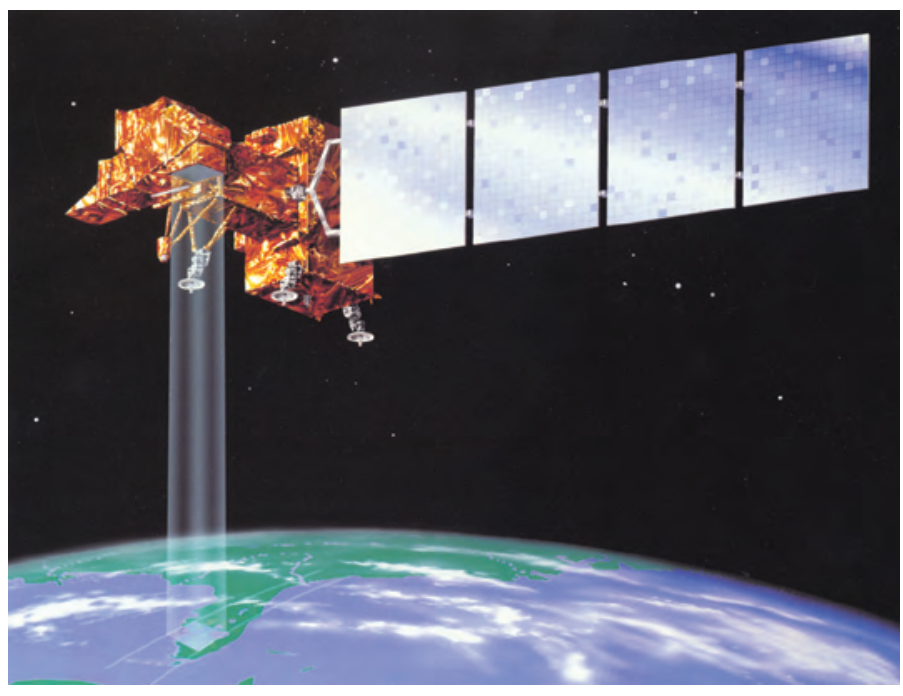

Figure 1. Landsat 7 Satellite.

was achieved on July 23, 1972, with the launch of Landsat 1, originally named "ERTS" for Earth Resources Technology Satellite. Landsat satellites have since provided the worldwide

\section{Approaching Four Decades of Earth Imaging}

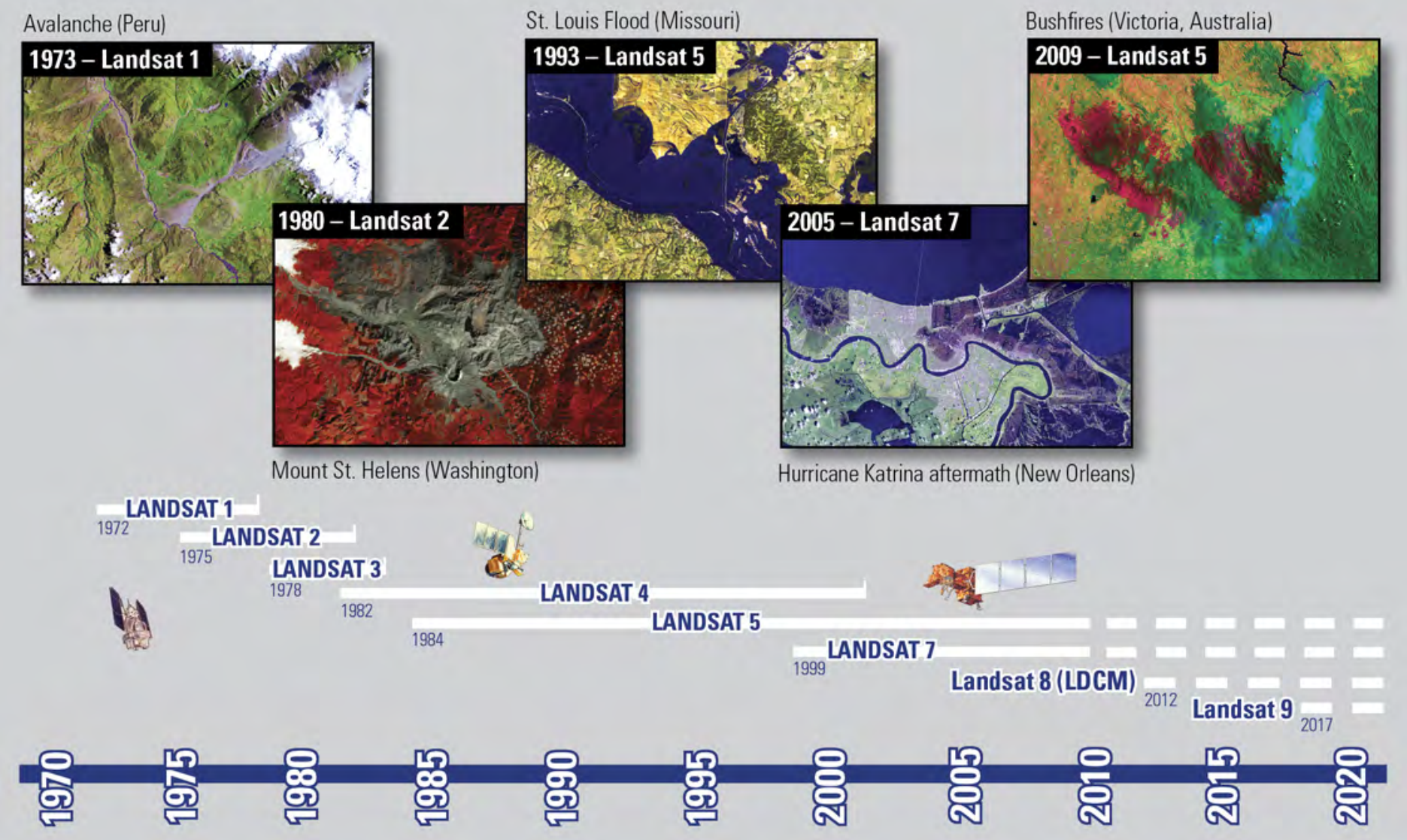


science and resource-management communities with an archive of space-based land remote sensing data - a valuable resource for people who work in agriculture, geology, forestry, education, regional planning, mapping, and global change research. Today, Landsat 5 (launched in 1984) and Landsat 7 (launched in 1999) continue to capture hundreds of additional images of the Earth's surface each day. Landsat 6 , the only satellite in the series not developed by NASA, failed at launch in 1993. The next generation land-observation system, the Landsat Data Continuity Mission (LDCM - to become Landsat 8 after launch), is intended to ensure continuity of Landsat data well beyond the duration of the Landsat 7 mission.

Table 1. Mission Dates and Sensors.

\begin{tabular}{llll}
\hline Satellite & Launched & Decommissioned & Sensors \\
\hline Landsat 1 & July 23, 1972 & January 6, 1978 & MSS/RBV* \\
Landsat 2 & January 22, 1975 & February 25, 1982 & MSS/RBV* \\
Landsat 3 & March 5, 1978 & March 31, 1983 & MSS/TM \\
Landsat 4 & July 16, 1982 & June 15, 2001 & MSS/TM \\
Landsat 5 & March 1, 1984 & Operational & MSS/TM \\
Landsat 6 & October 5, 1993 & Did not achieve & ETM** \\
& & orbit & \\
Landsat 7 & April 15, 1999 & Operational & ETM+** \\
\hline
\end{tabular}

*The return beam vidicon (RBV) was essentially a television camera and did not achieve the popularity of the MultiSpectral Scanner (MSS) sensor.

**The sensor onboard Landsat 6 was the Enhanced Thematic Mapper (ETM). Landsat 7 carries the ETM+.

Today, the USGS also leads a Landsat Science Team that develops and evaluates applications of next-generation satellite data, defines a global, long-term data acquisition plan, and advises the USGS on Landsat data requirements of the user community.

\section{Characteristics of the Landsat System}

Each Landsat satellite images the Earth's surface along the satellite's ground track in a 185 kilometer-wide (115 mile-wide) swath as the satellite moves in a descending orbit (moving from north to south) over the sunlit side of the Earth. Each satellite crosses every point on the Earth at nearly the same time once every 16 or 18 days, depending on its altitude. Landsats 1,2 , and 3 orbited at an altitude of 920 kilometers (572 miles), circling the Earth every 103 minutes. Landsats 4, 5, and 7 were placed in orbit at 705 kilometers (438 miles) altitude, circling the Earth every 99 minutes.

The primary sensor onboard Landsats 1, 2, and 3 was the Multispectral Scanner (MSS), with an image resolution of approximately 80 meters in four spectral bands ranging from the visible green to the near-infrared (IR) wavelengths (table 2). The MSS sensor on Landsat 3 included a fifth band in the thermal-IR wavelength.

The improved Thematic Mapper (TM) sensors onboard Landsats 4 and 5 were designed with several additional bands in the shortwave infrared (SWIR) part of the spectrum, plus an improved spatial resolution of 120 meters for the thermal-IR band and 30 meters for the other six bands (table 3 ).
Table 2. MSS Band Designation (Landsats 1, 2, and 3).

\begin{tabular}{|c|c|c|}
\hline $\begin{array}{c}\text { Landsats 1, 2, \& } 3 \\
\text { Spectral Bands }\end{array}$ & $\begin{array}{l}\text { Landsats } 4 \text { \& } 5 \\
\text { Spectral Bands }\end{array}$ & Use \\
\hline Band 4 - green & Band 1 - green & $\begin{array}{l}\text { Emphasizes sediment- } \\
\text { laden water and } \\
\text { delineates areas of } \\
\text { shallow water }\end{array}$ \\
\hline Band 5 - red & Band $2-$ red & $\begin{array}{l}\text { Emphasizes cultural } \\
\text { features }\end{array}$ \\
\hline Band 6 - near IR & Band 3 - near IR & $\begin{array}{l}\text { Emphasizes vegetation } \\
\text { boundary between land } \\
\text { and water, and } \\
\text { landforms }\end{array}$ \\
\hline Band 7 - near IR & Band 4 - near IR & $\begin{array}{l}\text { Penetrates atmosphere } \\
\text { haze best; emphasizes } \\
\text { vegetation, boundary } \\
\text { between land and water, } \\
\text { and landforms }\end{array}$ \\
\hline
\end{tabular}

Landsats 5 and 7 complete approximately 14 full orbits of the Earth per day. Each satellite has a 16-day full-Earth-coverage cycle, but their orbits are offset to allow 8-day repeat coverage of any Landsat "scene" area on the globe. Landsat 7 carries the Enhanced Thematic Mapper Plus (ETM+), with 30-meter visible and IR bands, a 60-meter spatial-resolution thermal band, and a 15-meter panchromatic band (table 3).

Table 3. TM and ETM+ Sensor Band Designations.

\begin{tabular}{|c|c|c|}
\hline \multicolumn{2}{|c|}{ Spectral Bands } & \multirow{2}{*}{$\begin{array}{l}\text { Use } \\
\text { Bathymetric mapping; distinguishes } \\
\text { soil from vegetation; deciduous from } \\
\text { coniferous vegetation }\end{array}$} \\
\hline 1 & Blue-green & \\
\hline 2 & Green & $\begin{array}{l}\text { Emphasizes peak vegetation, which is } \\
\text { useful for assessing plant vigor }\end{array}$ \\
\hline 3 & Red & Emphasizes vegetation slopes \\
\hline 4 & Reflected IR & $\begin{array}{l}\text { Emphasizes biomass content and } \\
\text { shorelines }\end{array}$ \\
\hline 5 & Reflected IR & $\begin{array}{l}\text { Discriminates moisture content of soil } \\
\text { and vegetation; penetrates thin clouds }\end{array}$ \\
\hline 6 & Thermal IR & $\begin{array}{l}\text { Useful for thermal mapping and } \\
\text { estimated soil moisture }\end{array}$ \\
\hline 7 & Reflected IR & $\begin{array}{l}\text { Useful for mapping hydrothermally } \\
\text { altered rocks associated with mineral } \\
\text { deposits }\end{array}$ \\
\hline 8 & Panchromatic & $\begin{array}{l}\text { Landsat } 7 \text { carries a panchromatic band } \\
\text { (visible through near infrared) with } \\
15 \text {-meter resolution for "sharpening" } \\
\text { of multispectral images }\end{array}$ \\
\hline
\end{tabular}

\section{Applications of Landsat Data}

Landsat data have been used by government, commercial, industrial, civilian, military, and educational communities throughout the United States and worldwide. The data support a wide range of applications in such areas as global change 
research, agriculture, forestry, geology, resource management, geography, mapping, water quality, and oceanography.

Landsats 5 and 7 continue to provide important observations of the Earth. The design of the Landsat 5 satellite, launched in 1984, has enabled it to last longer than anticipated. This satellite has established a tremendous record for reliability throughout 26 years of continuous operation — with a moving mirror assembly in the imaging instrument! Landsat 7, using a similar mirror assembly, continues to provide the global science community with a wealth of land-surface data. The LDCM satellite will use a solid-state "pushbroom" imaging instrument with no moving parts.

By February 2010, the network of USGS ground receiving stations had collected nearly 2.5 million Landsat scenes for the U.S. archive. This network, combined with Landsat 7's capability to record and play back images of foreign sites, enables full coverage of the Earth's land masses, although the satellite's orbit does not include direct overflight of the North or South Pole.

The consistency of Landsat data acquired through the years allows for direct comparison of current specific site images with those taken months, years, or decades earlier. This comparison process can reveal land-cover changes that occur slowly and subtly, or quickly and devastatingly. Pre- and post-event Landsat images also are invaluable for emergency response and disaster relief. Within hours of data acquisition, the USGS Earth Resources Observation and Science (EROS) Center in Sioux Falls, South Dakota, provides relief organizations worldwide with satellite images for disaster response, as well as image-derived products that incorporate information on population density, elevation, and other relevant topics.
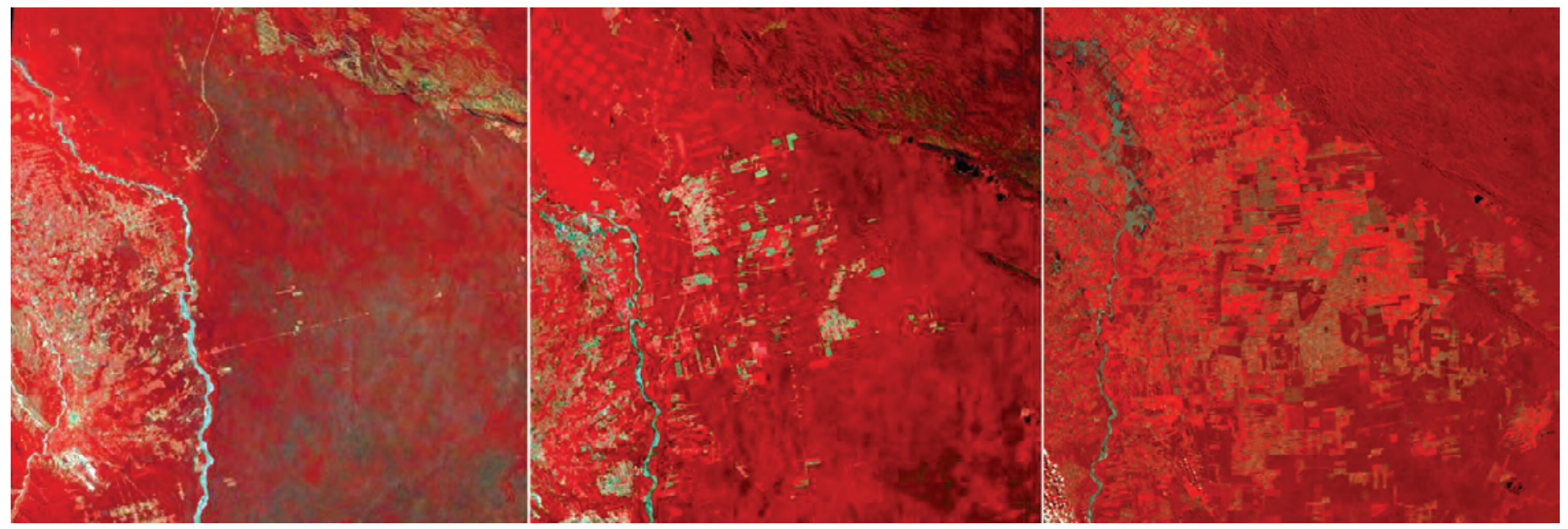

Figure 2. Progression of deforestation in Bolivia from 1975 to 2000 . The image on the left was acquired on June 17, 1975; the middle image on July 10, 1992; and the right image on August 1, 2000.
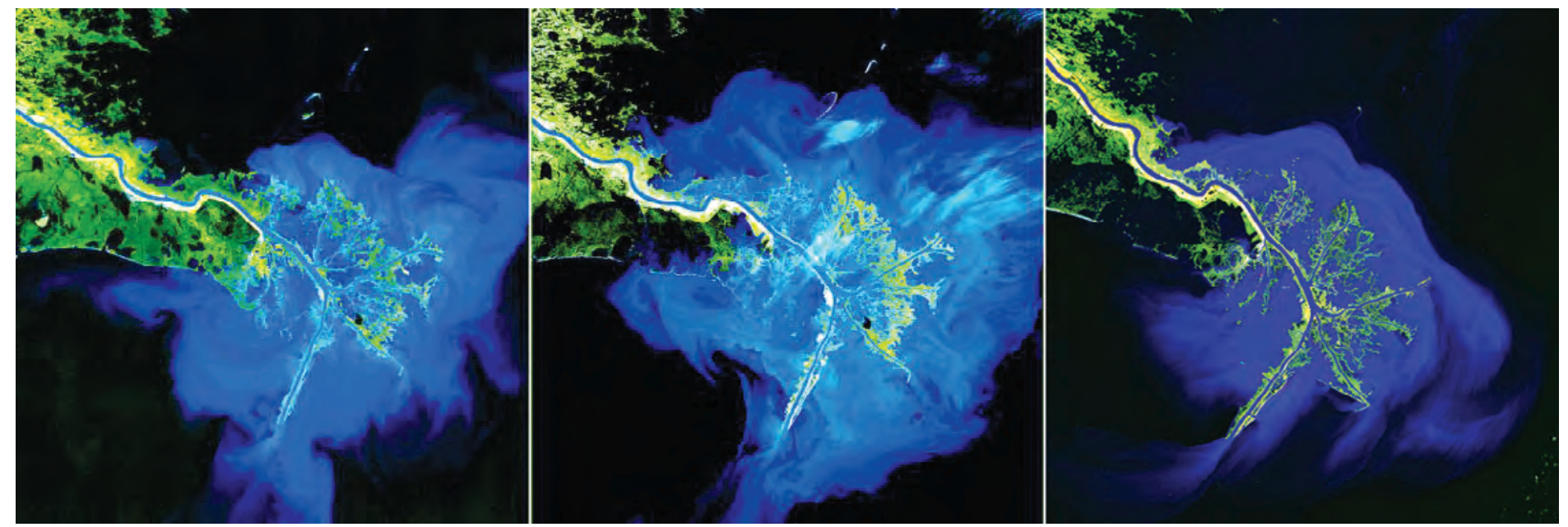

Figure 3. Three decades of Mississippi Delta sediment deposition from the Mississippi-Missouri River system eroded debris. The left image was acquired on January 16, 1973; the middle image on March 12, 1989; and the right image on January 6, 2003. 


\section{Landsat 7 ETM+ — Scan Line Corrector Failure}

On May 31, 2003, unusual artifacts began to appear within image data collected by the ETM+ instrument onboard Landsat 7. The problem was caused by failure of the Scan Line Corrector (SLC), which compensates for the forward motion of the satellite in each image. Subsequent efforts to recover the SLC were not successful. Without an operating SLC, the line of sight traces a zigzag pattern along the satellite ground track with resulting data gaps that form alternating wedges that increase in width from the center of the image to the edge; however, Landsat 7 is still capable of acquiring useful imagery worldwide with the SLC turned off, particularly within the central part of any given scene. The USGS has provided the user community with a method to fill gaps in one Landsat 7 scene using pixels from another scene of the same site taken shortly before or after the gap. Whether or not they choose to fill the gaps, many users continue to find Landsat 7 data to be useful, as tens of thousands of scenes are downloaded each week from the USGS.

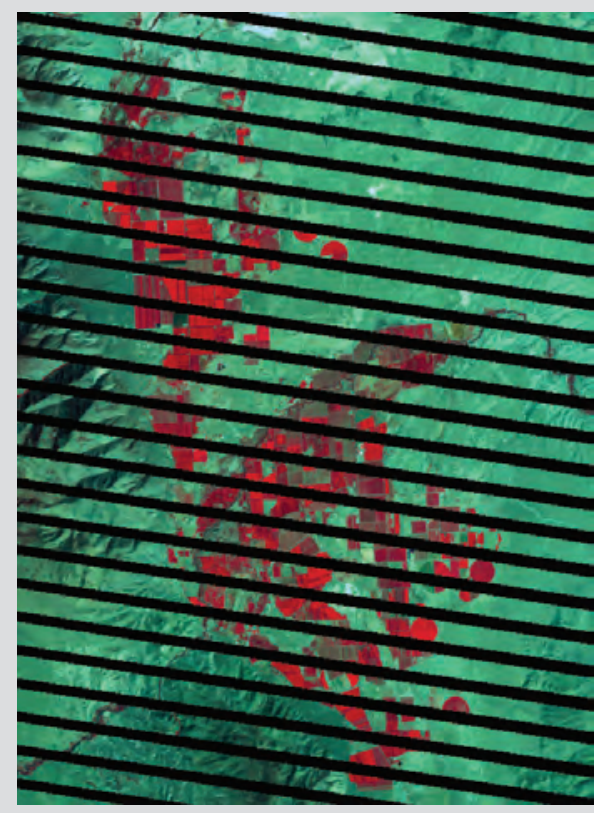

Figure 4. Agriculture in Nevada. Scan Line Corrector anomaly creates a zigzag pattern along satellite ground track. Image acquired August 28, 2003.

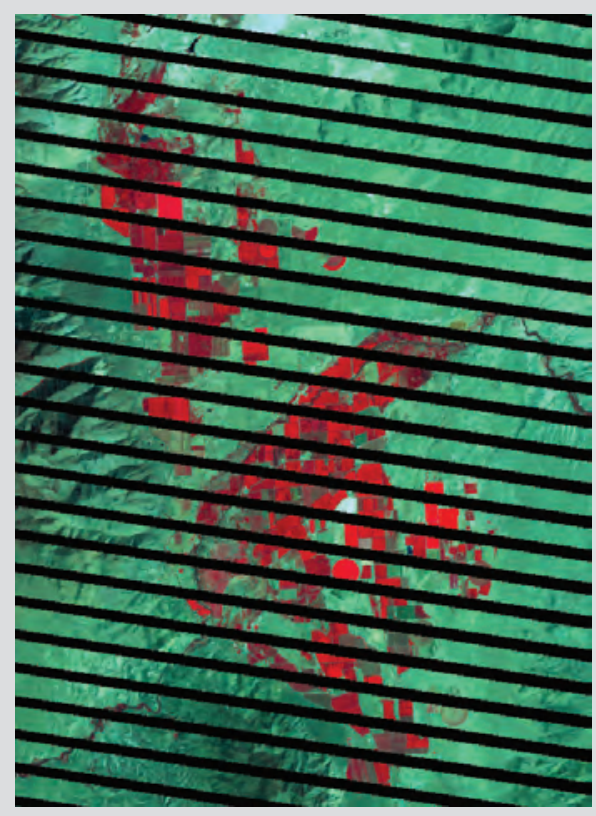

Figure 5. Agriculture in Nevada. An image collected at the same location, but on a different date, is used to fill the scan lines from the image in figure 4 . Scene acquired August 12, 2003.

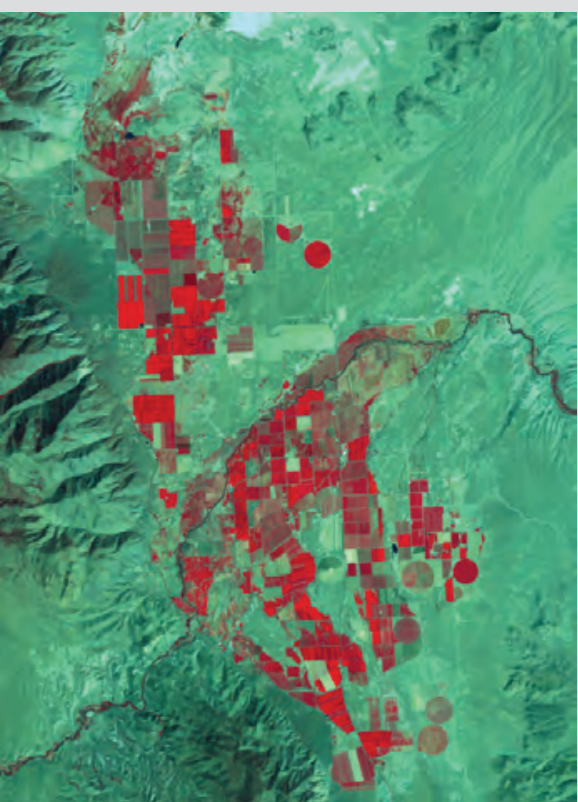

Figure 6. Agriculture in Nevada. Scenes from figures 4 and 5 are combined to form this final gap-filled image.

\section{Information}

All USGS Landsat data acquired from 1972 to the present are available over the Internet at no charge and with no user restrictions. To obtain data, see http://glovis.usgs.gov or http://earthexplorer.usgs.gov. For information about Landsat operations, technology, and product specifications, visit http:// landsat.usgs.gov, or contact:

\section{USGS EROS}

Customer Service

Mundt Federal Building

Sioux Falls, SD 57198

Telephone: 605-594-6151

Fax: 605-594-6589

Email: custserv@usgs.gov
For information about the USGS Land Remote Sensing Program, please visit http://remotesensing.usgs.gov.

For information about LDCM, please visit http://ldcm. usgs.gov.

For additional information about the USGS, visit http:// ask.usgs.gov or the USGS home page at http://www.usgs.gov. 